\title{
Cornea of Ommatidia in Lepidoptera (Insecta) - a Scanning Electron Microscope Study
}

\author{
Józef RAZOWSKI and Janusz WOJTUSIAK
}

Accepted January 25, 2006

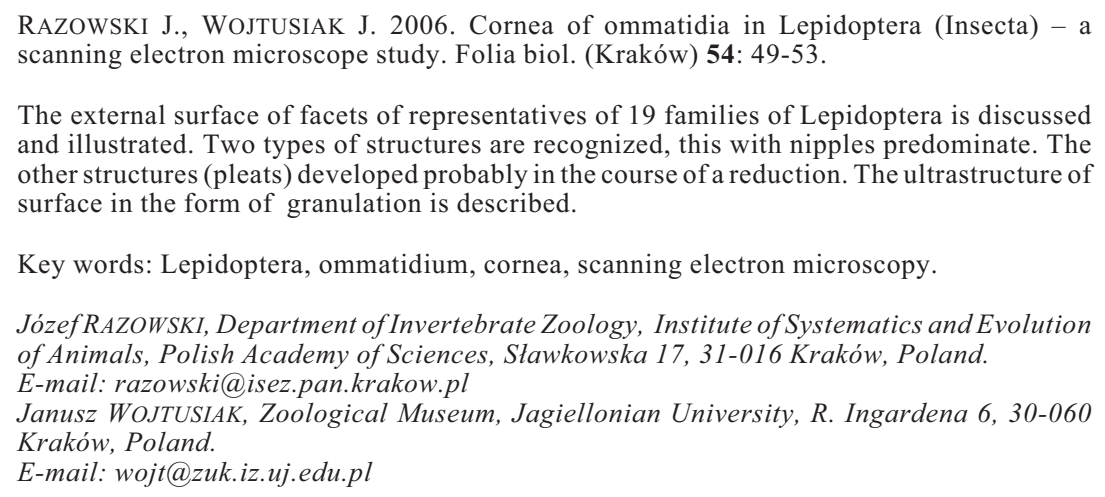

The outer surface of ommatidia in insects has long been treated as being smooth (e.g. by YAGI \& KOYAMA 1963). BERNHARD and MILLER (1962) in some Lepidoptera and later (RAZOWSKI \& WOJTUSIAK 2004) in some Tortricidae e.g. in Cnephasia incertana and Archips crataeganus, were the first to discover their complicated structure. Under the higher magnification (cf. illustrations) of the scanning electron microscope it is seen as a dense agglomeration of processes (approximately 25 per one square micrometer in $\mathrm{Ar}$ chips crataeganus), arranged in more or less long rows, forming altogether a kind of a brush. These processes are referred to as nipples.

The function of this structure was then hypothesized and explained by BERHARD (1967) and BERHARD and MILLER (1968).

Among the examined taxa there is another type of the outer surface of ommatidium devoid of any nipples but consisting of numerous irregular pleats. This type of surface, unknown to date in Lepidoptera, was already found in Musca domestica, Muscidae, Diptera by BERNHARD (1967).

\section{Material and Methods}

Material

In course of the present study 23 species of Lepidoptera belonging to 21 families were examined, from the most primitive among the European taxa to highly specialized ones.

List of studied taxa:

Micropterigidae: Micropterix calthella (Linnaeus)

Nepticulidae: Fomoria septembrella (Stainton)

Adelidae: Nemophora metallica (Poda)

Incurvariidae: Incurvaria muscalella ([Denis \& Schiffermüller])

Yponomeutidae: Yponomeutinae: Yponomeuta plumbella ([Denis \& Schiffermüller]), Swammerdamia caesiella (Hübner)

Argyresthinae: Argyresthia spinosella Stainton Plutellidae: Plutella xylostella (Linnaeus)

Zygaenidae: Zygaena filipendulae (Linnaeus)

Sesiidae: Synanthedon tipuliformis (Clerck)

Cossidae: Cossus cossus (Linnaeus)

Tortricidae: Cnephasia incertana (Treitschke), Archips crataeganus (Scopoli)

Pterophoridae: Pterophorus pentadactyla (Linnaeus)

Pyralidae: Pleuroptyla ruralis (Scopoli)

Lasiocampidae: Dendrolimus pini (Linnaeus)

Saturniidae: Saturnia pavonia (Linnaeus)

Sphingidae: Deilephila elpenor (Linnaeus)

Lycaenidae: Maculinea teleius (Bergsträsser) 
Nymphalidae: Nymphalinae: Vanessa atalanta (Linnaeus)

Satyrinae: Cheimas opalinus (Staudinger)

Notodontidae: Notodonta dromedarius (Linnaeus)

Noctuidae: Noctua pronuba (Linnaeus)

\section{Methods}

Dry specimens were used; the eyes were dusted with gold in a vacuum chamber and their structures were observed and photographed by means of a Field Emission Scanning Electron Microscope Hitachi S-4700 by courtesy of Scanning Electron Microscopy Unit of the Faculty of Biological Sciences, Jagiellonian University, Kraków.

\section{Results}

There are two types of outer structure of the cornea in Lepidoptera. Type one with nipples present and type two with pleats.

Type one appears in Micropterix calthella (Figs 1,2) and Plutella xylostella (Figs 3, 4). The nipples are slender, circular in transverse section, equally distanced from one another, forming regular rows on the outer surface of facets. This regularity is weaker in the intervenal spaces (Figs 4, 5). In the former species the number of nipples is much higher than in P. xylostella. The localization of nipples in P.xylostella is illustrated in a longitudinal section of cornea by WANG \& HSU (1982). The density of nipples on facets is probably speciesspecific but not characteristic of the families. In Notodonta dromedarius (Fig. 6) these distances are at average as large as the diameters of nipples, however, in Zygaena filipendulae (Fig. 7) the arrangement of the nipples is very dense. In the latter the transverse section of nipples is analogical to that of the facets as they become hexagonal, more or less regular. In all other species examined, except for those mentioned as type two, the shapes and arrangements of nipples are rather uniform.

Intermediate forms. The surface of the ommatidium of Notodonta dromedarius (Fig. 6) is certainly of the type one, e.g. with distinct but short nipples. They are irregularly arranged, rounded apically or somewhat elongate. Some elongate ones show distinct fusions of two neighboring simple nipples. The distances between the nipples are large. The irregularity of the arrangement of nipples and a diminution of spaces between them are found in Zygaena filipendulae (Fig. 7).

Type two - pleats. They are found in Yponomeutidae in two species, viz., Yponomeuta plumbella (Figs 8-10) and Swammerdamia caesiella (Fig. 11). The pleats cover the entire outer surfaces of each facet and their density in median parts and the margins is the same. They were not found in the interfacetal spaces. They are irregularly high, being slightly depressed between rounded convexities. Some parts of these structures are very short and are reminiscent of solitary nipples of type one. The single convexities are innumerous, entirely or in part isolated from the pleats. The concavities are variably sized and deep.

An intermediate structure of the outer surface of facets is found in Saturnia pavonia, Saturniidae (Fig. 12). Pleats are short or represented by separate convexities, two or three in a series and the spaces between them are rather irregular and shallow, diffusely edged. In Cossus cossus, Cossidae (Fig. 13) the nipples are still preserved, separate but irregularly arranged and the spaces between them are narrow.

\section{Ultrastructure of cornea}

In all examined species small, rounded or elliptic convexities occur referred to here as granules. On the top parts of the nipples they are dense and arranged rather irregularly e.g. in Micropterix calthella (Figs 13, 14) and in Cheimas opalinus (Fig. 15) or form indistinct rows (e.g. in Deilephila elpenor). Their size is not species-specific (e.g. they are much larger in Noctua pronuba than in Pterophorus pentadactylus). They certainly occur also on the lateral surfaces (not examined but some granules are seen in Fig. 15 in Cheimas), between nipples (in Cossus cossus, Fig. 13), and in between the pleats (Fig. 10, Yponomeuta plumbella). The role of granules is not known but they are probably of optical importance. Judging from their distribution they develop before the formation of nipples.

\section{Discussion}

Type one structure (nipples) is found in the majority of families, type two (pleats ) is found only in one examined family (Yponomeutidae). However, there is one exception in the subfamily Argyresthiinae (Argyresthia spinosella) in which the nipples are fully developed. Intermediate forms were found in Cossus cossus and Saturnia pavonia.

Type one is more generalized as nipples are found in the primitive family of Micropterigidae. Type two was probably developed by a reduction of spaces between nipples and fusion of some of them. The presence of these two types is not correlated systematically nor with the mode of activity of the moths. 

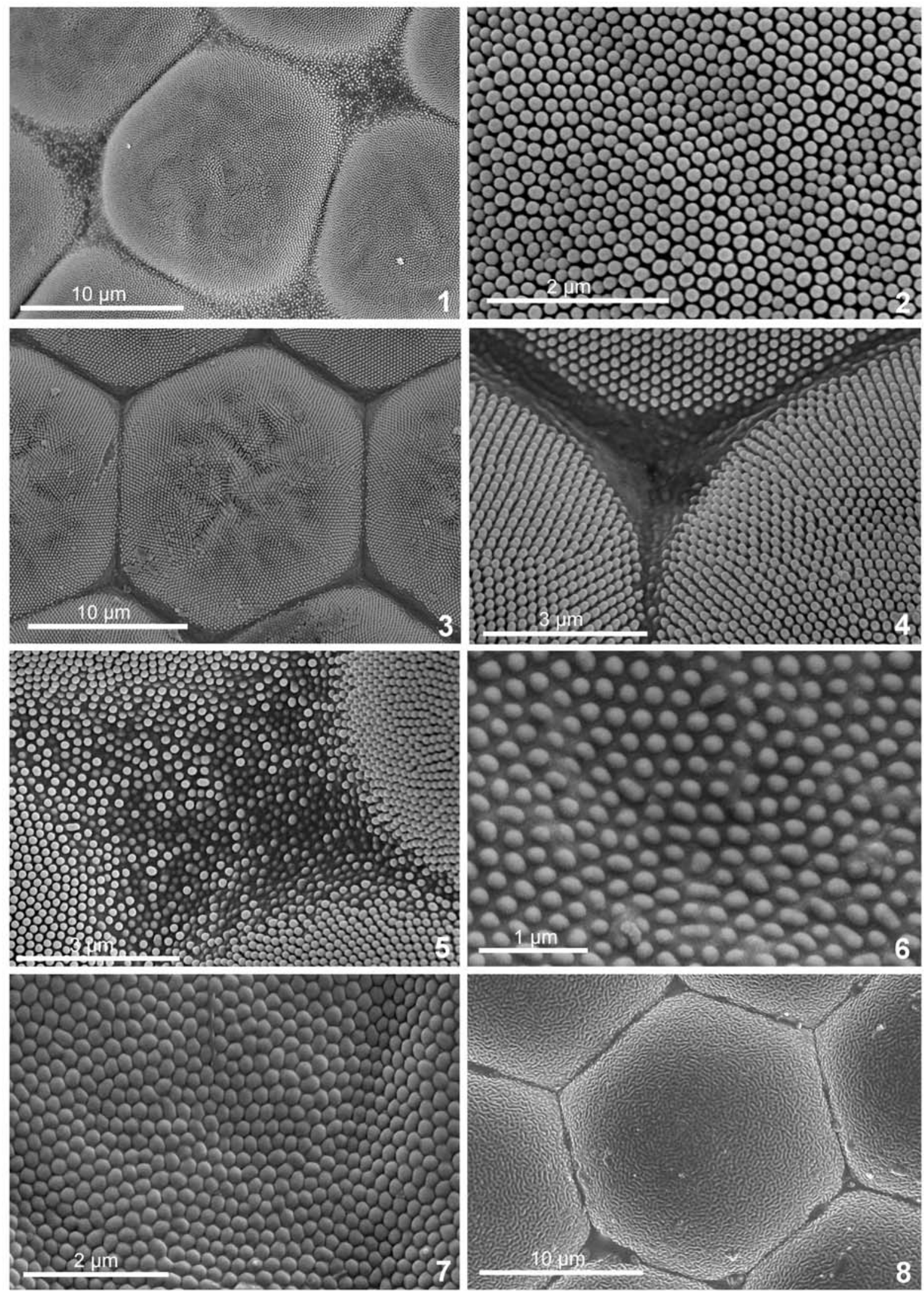

Figs 1-8. Fig. 1. Arrangement of nipples in Micropterix calthella, Fig. 2. Micropterix calthella, fragment of cornea, Fig. 3. Facet of Plutella xylostella, Fig. 4. Intervenal space of Plutellaxylostella, Fig. 5. Intervenal space of Micropterix calthella, Fig. 6. Arrangement of nipples of Notodonta dromedaries, Fig. 7. Arrangement of nipples of Zygena filipendulae, Fig. 8. Facets of Yponomeuta plumbella. 

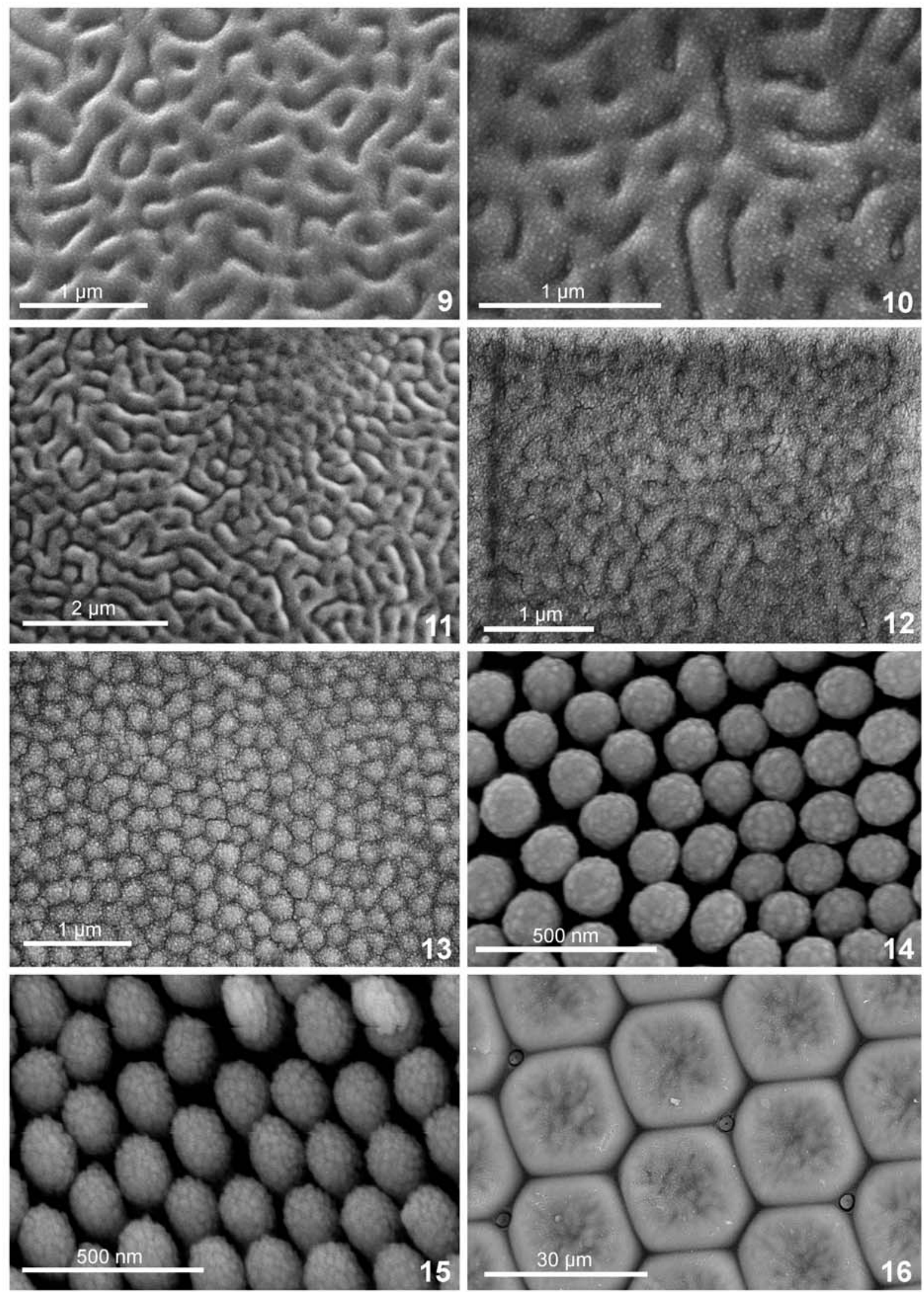

Figs 9-16. Fig. 9. Pleats of Yponomeuta plumbella, Fig. 10. Pleats of Yponomeuta plumbella with granulations seen, Fig. 11. Pleats of Swammerdania caesiella, Fig. 12. Intermediate structure of cornea in Saturnia pavonia, Fig. 13. Intermediate structure of cornea in Cossus cossus, Fig. 14. Granules of nipples in Micropterix calthella, Fig. 15. Granules of nipples in Cheimas opalinus, Fig 16. Transverse section through interfacetal hairs of Vanessa atalanta. 
The nipples occur on the whole surface of the cornea but are less abundant in the intervenal areas (Figs 1,5).

Additional microstructure, granulation, was discovered on the cornea. The granules occur both on the outer surfaces of the pleats, nipples and between them (as seen in Figs 10, 13).

\section{Appendix}

Interfacetal hair. The shapes of hairs are rather well known. The only case presented here is the transverse section of the hair in Vanessa atalanta (Fig. 16) with a distinct inner channel.

\section{Acknowledgements}

The authors are much indebted to Mrs Jadwiga FABER and Mrs Zuzanna BANACH for their help in making SEM photographs and to Mr Artur CZEKAJ for arrangement of illustrations.

\section{References}

BERNHARD C. G. 1967. Structural and functional adaptation in a visual system. Endevour 26: 79-84.

Bernhard C. G., Miller W. H. 1962. A corneal nipple pattern in insect compound eyes. Acta physiol. Scand. 56: 385-386.

Bernhard C. G., Miller W. H. 1968. Evidence for visual function of corneal interference filters. J. Insect Physiol. 17: 2287-300.

RAZOWSKI J., WOJTUSIAK J. 2004. A few characters of the adult compound eye and its peripheral area in some Tortricidae (Insecta: Lepidoptera). Genus 15: 267-274.

WANG C-H., HSU S.-J. 1982. The compound eye of diamondback moth, Plutella xylostella (L.) and its pigment migration. Bull. Inst. Zool. Acad. Sinica 21: 75-92.

YAGi N., KoYAMA, N. 1963. The compound eye of the Lepidoptera. Approach from organic evolution. Shinkyo-Press, Tokyo. 319 pp. 